\title{
PRÁTICAS DO ENSINO DE MÚSICA E CANTO ORFEÔNICO NO GINÁSIO PARANAENSE (1931-1961)
}

\author{
Wilson Lemos Junior ${ }^{*}$
}

\section{RESUMO}

Entre os anos de 1931 e 1961, a disciplina de música e canto orfeônico passou a ser adotada oficialmente nos currículos das escolas ginasiais brasileiras. Utilizando fontes encontradas em relatórios nos arquivos do Colégio Estadual do Paraná, são investigadas as práticas relacionadas ao ensino de música e canto orfeônico no Ginásio Paranaense entre os anos de 1931 a 1961.

Palavras-chave: história da educação, educação musical, escola secundária.

* Instituto Federal do Paraná (IFPR), Curitiba/PR, Brasil. 


\title{
PRÁCTICAS DE LA EDUCACIÓN DE MÚSICA Y CANCIÓN ORFÓNICA EN EL GIMNASIO PARANAENSE (1931-1961)
}

\section{RESUMEN}

Entre 1931 y 1961, la disciplina de la música y el canto orfeónico se adoptó oficialmente en el plan de estudios de las escuelas secundarias brasileñas. Utilizando fuentes encontradas en informes en los archivos del Colegio Estatal de Paraná, se investigan las prácticas relacionadas con la enseñanza de la música y el canto orfeónico en el Gymnasium Paranaense entre los años 1931 a 1961.

Palabras clave: historia de la educación, educación musical, bachillerato.

\section{PRACTICES OF MUSIC AND ORPHONIC SONG EDUCATION IN PARANAENSE GYM (1931-1961)}

\begin{abstract}
Between 1931 and 1961, the discipline of music and orpheonic singing was officially adopted in the Brazilian secondary school study plan. Using sources found in information in the archives of the State College of Paraná, we investigate the practices related to the teaching of music and orpheonic singing in the Paranaense Gymnasium between 1931 and 1961.
\end{abstract}

Keywords: history of education, music education, high school.

\section{PRATIQUES D'ÉDUCATION À LA MUSIQUE ET À LA CHANSON ORPHONIQUE AU PARANAENSE GYM (1931-1961)}

\section{RÉSUMÉ}

Entre 1931 et 1961, la discipline de la musique et du chant orphonique a été officiellement adoptée dans les programmes des collèges brésiliens. À partir de sources trouvées dans des archives des archives du collège d'État de Paraná, les pratiques relatives à l'enseignement de la musique et du chant orphonique au Gymnasium Paranaense entre 1931 et 1961 font l'objet d'une enquête.

Mots-clés: histoire de l'éducation, éducation musicale, lycée. 


\section{INTRODUÇÃO}

A partir do ano de 1931, a disciplina de música e canto orfeônico passou a ser adotada oficialmente nos currículos do curso ginasial ${ }^{1}$ das escolas secundárias brasileiras. Essa inclusão ocorreu graças ao projeto apresentado por Heitor Villa-Lobos ao então presidente Getúlio Vargas, que sugeria a adoção do canto orfeônico como disciplina obrigatória na escola em todos os níveis de ensino. Porém, a inclusão do canto orfeônico como disciplina obrigatória, ocasionou uma nova particularidade, pois as escolas deveriam se adequar para esta nova prática.

Segundo Igayara-Souza (2019, p. 211):

A prática musical esteve no centro da atividade musical na escola do século XX. A análise das publicações de manuais e coletâneas para uso escolar demonstrou a importância dada às habilidades de leitura e entoação, praticadas como exercício de solfejo, e às performances musicais, geralmente em festas e comemorações escolares, com as coletâneas provendo o repertório de hinos e canções a serem selecionados, de acordo com a ocasião.

O presente estudo trata de investigar algumas dessas práticas escolares do Ginásio Paranaense², atual Colégio Estadual do Paraná em relação ao ensino do canto orfeônico. A pesquisa fundamenta-se nas análises do campo da história das disciplinas escolares, com destaque para a história dos conteúdos. Segundo Souza Junior e Galvão (2020, p. 393):

Chervel (1990) afirma que a especificidade desse campo de estudos reside na investigação dos ensinos da idade escolar, pois o seu elemento central é a história dos conteúdos. Nesse campo, é possível investigar a

\footnotetext{
${ }^{1} \mathrm{O}$ curso ginasial fazia parte do ensino secundário e equivale atualmente ao período de $6^{\circ}$ ao $9^{\circ}$ ano do curso fundamental II. Na época, o termo ginasial era grafado como gymnasial. Optou-se nesse artigo por utilizar a nomenclatura atual do termo.

${ }^{2}$ O Ginásio Paranaense foi criado em 1918. No ano de 1943, passou a se chamar Colégio Estadual do Paraná.
} 
relação entre o que foi estabelecido como finalidade para os conteúdos de ensino e o que foi efetivamente ensinado/aprendido. Enfim, não é um campo que estuda a história das idéias pedagógicas, do discurso pedagógico oficial, das políticas educacionais, já que tais elaborações visam mais freqüentemente, em geral de forma positiva, corrigir um estado de coisas, modificando certas práticas, do que propriamente representar a realidade. Por outro lado, o campo da História das Disciplinas Escolares procura enfatizar o porquê de a escola ensinar o que ensina, em vez de tentar responder o que a escola deveria ensinar.

Com isso, busca-se estabelecer uma aproximação da história da educação musical com o campo da história da educação, pelo viés da história das disciplinas. Porém, deve-se destacar que as pesquisas no campo da história da educação musical vêm se constituindo há várias décadas no Brasil. Porém, destaca-se que:

Recentemente, em 2015, a Associação Brasileira de Educação Musical, criou o G.T 1.3: Grupo de Trabalho História da Educação Musical, com o objetivo de reunir trabalhos específicos, o que consideramos ter sido um importante passo para a consolidação dessas pesquisas. Atualmente, há três Grupos de Pesquisas registrados no CNPq que se dedicam a pesquisas nesse âmbito: GEPEAMUS, NEHEMus e GEPEMAC (MONTI; ROCHA, 2019, p. 19).

Objetiva-se por meio das práticas educacionais relacionadas ao ensino de música e canto orfeônico, apresentar a experiência desta disciplina em contexto regional. Para isso, são utilizadas fontes encontradas nos relatórios armazenados nos arquivos do Colégio Estadual do Paraná, além de artigos publicados em meios de comunicação tanto em jornais de grande circulação como Gazeta do Povo, Jornal de Antonina, Jornal O Dia, quanto do jornal escolar O Colégio Estadual do Paraná. Esses artigos foram catalogados na Biblioteca Pública do Paraná, em microfilme contendo diversos arquivos sobre a vida de Bento Mossurunga3,

3 O professor Bento João de Albuquerque Mossurunga (1879-1970) foi maestro, pianista, violinista, regente e compositor. Mesmo que a maioria dos documentos apresente a grafia correta do sobrenome do professor, alguns documentos apresentam o sobrenome grafado como Mussurunga. 
professor de canto orfeônico no Ginásio Paranaense.

O estudo se encontra dividido em três partes. A primeira parte trata de uma análise a respeito do rendimento escolar dos alunos, a partir de 1946 quando ficou estabelecida a obrigatoriedade da avaliação para o ensino de canto orfeônico. A segunda parte aborda a questão das apresentações orfeônicas realizadas pelos estudantes da instituição e a terceira trata da estrutura do Ginásio Paranaense/CEP para o ensino de canto orfeônico.

O período abordado privilegia o interstício entre a reforma Francisco Campos, ocorrida no ano de 1931, que tornou obrigatório o ensino de música e canto orfeônico em território nacional até a promulgação da Lei de Diretrizes e Bases da Educação Nacional n. ${ }^{\circ}$ 4.024/61 que decretou o fim do canto orfeônico, substituído pela disciplina de música, que passou a figurar entre as disciplinas optativas.

\section{O RENDIMENTO DOS ESTUDANTES DO GINÁSIO PARANAENSE/ COLÉGIO ESTADUAL DO PARANÁ NAS AVALIAÇÕES DE CANTO ORFEÔNICO}

Em 1946, por meio do Decreto-lei n. ${ }^{\circ} 9.494$ de 22 de julho de 1946, foi oficializada a obrigatoriedade da avaliação para o ensino de canto orfeônico no ensino ginasial. A legislação estabelecia que cada estudante deveria receber uma nota mensal de acordo com o resultado de sua avaliação. A nota mensal deveria ser formada por exercícios orais e práticos realizados nas aulas de canto orfeônico. Destaca-se que os exercícios abordavam elementos de teoria musical retirados de um trecho de uma obra didática, hinos ou canções, em conformidade com as orientações do Conservatório Nacional de Canto Orfeônico. As provas parciais deveriam seguir a mesma orientação dos exercícios mensais, sendo, porém, de caráter individual: 
As provas finais realizar-se-ão por grupos de quatro alunos no máximo.

Nessas provas deverá ser verificado o aproveitamento em afinação, ritmo, dicção, atitude e disciplina do conjunto.

Para os alunos desafinados será obedecido o critério de julgamento traçado pelo Conservatório Nacional de Canto Orfeônico (BRASIL, 1946).

Além do expresso acima, havia uma ênfase para que fossem evitados nas avaliações práticas, "problemas de natureza puramente teóricos” (BRASIL, 1946). Para os estudantes que apresentassem problemas de afinação havia algumas determinações traçadas pelo Conservatório Nacional de Canto Orfeônico. Dentre estas orientações, encontra-se um destaque sobre a importância de não baixar as notas de tais alunos. Isto demonstra um dos problemas enfrentados nas aulas de canto orfeônico: a heterogeneidade das turmas. Os professores teriam de ensinar a prática vocal para turmas desiguais em nível de rendimento e assimilação (LEMOS, 2005).

A preocupação com os estudantes menos hábeis no ensino musical também esteve presente em publicações de Villa-Lobos e de Barreto (1938, p. 63), que afirmava que:

[...] nem todos têm a mesma facilidade em reconhecer auditivamente a justeza e altura exata dos sons, avaliar da sua intensidade, distinguir facilmente as consonâncias, discriminar os timbres e perceber concientemente o ritmo, embora reagindo instintivamente a êle.

A preocupação apresentada pela legislação, por Villa-Lobos e Barreto (1938), revelava dúvidas relacionadas à obrigatoriedade da avaliação no ensino de música: quais seriam os impactos desta avaliação? Quantos alunos apresentariam um rendimento muito baixo? Como proceder diante de estudantes com dificuldades para a prática musical?

Na busca de elucidar algumas destas questões, priorizou-se neste tópico, investigar os rendimentos dos estudantes do Colégio Estadual do Paraná na 
disciplina de canto orfeônico, uma vez que a partir de 1947 são encontradas atas de provas, atendendo a obrigatoriedade das avaliações para o ensino de canto orfeônico. A partir dos boletins dos estudantes, encontrados em relatórios armazenados no arquivo do Colégio Estadual do Paraná, foi produzido uma tabela de rendimentos dos alunos nas provas finais de canto orfeônico no Colégio Estadual do Paraná nos anos de 1947 e 1953 (Tabela 1). As datas priorizadas na tabela foram àquelas encontradas no momento da catalogação dos arquivos. Sendo assim, trata-se de uma amostra, da qual foram excluídos os estudantes desistentes da média geral da turma:

Tabela 1 - O rendimento escolar dos alunos do Colégio Estadual do Paraná (1947-1953).

\begin{tabular}{|c|c|c|c|c|}
\hline ANO & TURMA & $\begin{array}{l}\text { NÚMERO DE } \\
\text { ESTUDANTES }\end{array}$ & $\begin{array}{c}\text { MÉDIA } \\
\text { GERAL DA } \\
\text { TURMA }\end{array}$ & $\begin{array}{c}\text { ALUNOS COM } \\
\text { NOTA ABAIXO DA } \\
\text { MÉDIA } \\
\text { (Abaixo de 5,o) }\end{array}$ \\
\hline 1947 & $1^{\mathrm{a}} 1^{\mathrm{a}}$ & 31 & $5 \cdot 5$ & 1 \\
\hline 1947 & $1^{\mathrm{a}} 2^{\mathrm{a}}$ & 34 & 4.9 & 16 \\
\hline 1947 & $1^{\mathrm{a}} 3^{\mathrm{a}}$ & 35 & 6.0 & 2 \\
\hline 1947 & $1^{a} 4^{a}$ & 35 & 6.1 & 1 \\
\hline 1947 & $1^{\mathrm{a}} 5^{\mathrm{a}}$ & 29 & $5 \cdot 5$ & 5 \\
\hline 1947 & $1^{\mathrm{a}} 6^{\mathrm{a}}$ & 28 & 6.5 & $\mathrm{O}$ \\
\hline 1947 & $1^{\mathrm{a}} 7^{\mathrm{a}}$ & 29 & 6.0 & 1 \\
\hline 1947 & $2^{\mathrm{a}} 1^{\mathrm{a}}$ & 33 & 5.9 & 3 \\
\hline 1947 & $2^{\mathrm{a}} 2^{\mathrm{a}}$ & 38 & 6.6 & o \\
\hline 1947 & $2^{\mathrm{a}} 3^{\mathrm{a}}$ & 29 & 4.9 & 9 \\
\hline 1947 & $2^{a} 4^{a}$ & 34 & 6.5 & o \\
\hline 1947 & $2^{\mathrm{a}} 5^{\mathrm{a}}$ & 34 & 6.2 & o \\
\hline 1947 & $4^{\mathrm{a}} 1^{\mathrm{a}}$ & 40 & 6.5 & o \\
\hline 1947 & $4^{\mathrm{a}} 2^{\mathrm{a}}$ & 41 & 6.9 & 0 \\
\hline
\end{tabular}




\begin{tabular}{|c|c|c|c|c|}
\hline ANO & TURMA & $\begin{array}{l}\text { NÚMERO DE } \\
\text { ESTUDANTES }\end{array}$ & $\begin{array}{l}\text { MÉDIA } \\
\text { GERAL DA } \\
\text { TURMA }\end{array}$ & $\begin{array}{c}\text { ALUNOS COM } \\
\text { NOTA ABAIXO DA } \\
\text { MÉDIA } \\
\text { (Abaixo de } 5,0)\end{array}$ \\
\hline 1953 & $1^{\mathrm{a}} 1^{\mathrm{a}}$ Masculino & 32 & 7.1 & 1 \\
\hline 1953 & $1^{\mathrm{a}} 2^{\mathrm{a}}$ Masculino & 28 & 6.4 & 2 \\
\hline 1953 & $1^{\mathrm{a}} 3^{\mathrm{a}}$ Masculino & 17 & 5.1 & 5 \\
\hline 1953 & $1^{\mathrm{a}} 1^{\mathrm{a}}$ Feminino & 34 & 7.1 & $\mathrm{O}$ \\
\hline 1953 & $1^{\mathrm{a}} 2^{\mathrm{a}}$ Feminino & 33 & 6.3 & 4 \\
\hline 1953 & $2^{\mathrm{a}} 1^{\mathrm{a}}$ Masculino & 33 & 7.6 & 3 \\
\hline 1953 & $2^{\mathrm{a}} 2^{\mathrm{a}}$ Masculino & 34 & 7.1 & 1 \\
\hline 1953 & $2^{\mathrm{a}} 1^{\mathrm{a}}$ Feminino & 34 & 7.6 & $\mathrm{O}$ \\
\hline 1953 & $2^{\mathrm{a}} 2^{\mathrm{a}}$ Feminino & 29 & $5 \cdot 7$ & 3 \\
\hline 1953 & $3^{\mathrm{a}} 1^{\mathrm{a}}$ Masculino & 35 & 8.3 & $\mathrm{O}$ \\
\hline 1953 & $3^{\mathrm{a}} 2^{\mathrm{a}}$ Masculino & 31 & 8.1 & $\mathrm{O}$ \\
\hline 1953 & $3^{\mathrm{a}} 1^{\mathrm{a}}$ Masculino & 26 & 7.9 & $\mathrm{O}$ \\
\hline 1953 & $3^{\mathrm{a}} 2^{\mathrm{a}}$ Feminino & 33 & 8.8 & $\mathrm{O}$ \\
\hline 1953 & $4^{\mathrm{a}} 1^{\mathrm{a}}$ Masculino & 32 & 8.2 & o \\
\hline 1953 & $4^{\mathrm{a}} 2^{\mathrm{a}}$ Masculino & 26 & $7 \cdot 4$ & $\mathrm{O}$ \\
\hline 1953 & $4^{\mathrm{a}} 1^{\mathrm{a}}$ Feminino & 33 & 8.6 & $\mathrm{O}$ \\
\hline 1953 & $4^{\mathrm{a}} 2^{\mathrm{a}}$ Feminino & 29 & 8.2 & $\mathrm{O}$ \\
\hline
\end{tabular}

Fonte: Elaborado pelo autor a partir dos relatórios do Colégio Estadual do Paraná.

Algumas análises podem ser feitas a partir do quadro de rendimento escolar dos alunos do Colégio Estadual do Paraná. A primeira delas é o fato de que as notas dos alunos da $1^{\mathrm{a}}$ série são mais baixas do que os estudantes de outras séries, o que poderia indicar um despreparo dos mais jovens em relação ao nível dos conteúdos aplicados nas avaliações do curso ginasial.

Outra constatação diz respeito ao fato das notas referentes ao ano de 1947 
serem muito baixas quando comparadas àquelas relativas ao ano de 1953. Isto, de certa forma, traz indícios sobre o efeito imediato da obrigatoriedade de provas para a disciplina de canto orfeônico. Aspectos como a heterogeneidade das turmas, a dificuldade de assimilação do conteúdo por parte do estudante, e o reduzido número de aulas de música, aliados ao grau de dificuldade dos conteúdos encontrados nas avaliações de 1947, podem ser considerados como fatores marcantes para o aparente fracasso, pelo menos em termos avaliativos, dos alunos do curso ginasial. Além disso, havia a possível falta de interesse dos alunos com o ensino de música, conforme relata Barreto (1938, p. 19), ao denunciar os problemas comuns envolvendo o ensino do canto orfeônico na escola:

\section{Quanto aos alunos:}
A. indiferença pelo estudo de música, principalmente no da leitura musical;
B. tendência a forçar a voz, gritando em vez de cantar;
C. deficiência de ritmo;
D. nenhuma atenção à significação e expressão da canção;
E. má pronúncia no canto;
F. pouca obediência à regência;
G. falta de pontualidade às aulas.

Alguns tópicos privilegiados pela autora como, por exemplo, a indiferença ao estudo de música, a falta de atenção e de pontualidade nas aulas, traz a ideia de que havia certo desinteresse dos alunos pelas aulas de música e canto orfeônico. Uma das possibilidades deste desinteresse poderia ser a dificuldade do estudante em compreender a complexa teoria musical apresentada. Outra possibilidade poderia ser a falta de coerência entre o conteúdo musical erudito e a música que o aluno estava habituado a ouvir. Devese destacar que o ensino de música e canto orfeônico evidenciava uma preocupação em ensinar a "boa música", excluindo aquela de apelo puramente 
comercial, uma vez que, segundo relata Sevcenko (1992), desde a década de 1920, o mercado fonográfico crescia e havia um grande número de jovens seduzidos pelas modernas músicas e danças da moda como o maxixe, o foxtrot, o jazz e o tango. Sevcenko (1992, p. 90) afirma também que a expansão da vitrola, se relacionava diretamente com a música da moda, na cidade de São Paulo durante a década de 1920:

[...] o gramofone estivera associado com as audições privadas, no lar, em família, de música erudita ou óperas, a vitrola se oferecia para audições públicas de jovens excitados com o frenesi de bandas estridentes, que é aliás o que passa a predominar no mercado de discos, como informa a propaganda da Casa Murano. Noutro comercial da mesma casa, a mensagem era mais apelativa: 'Dance muito!! [...] e divirta-se que a vida é curta!'.

O sucesso das vitrolas e da dança entre os jovens era cada vez mais evidente e estava cada vez mais fortalecido pela expansão nacional da indústria fonográfica. De acordo com o artigo encontrado em um jornal católico $O$ Domingo, de autoria do padre Borromeu (1955):

\begin{abstract}
É Pecado Dansar?
Como cristãos devemos evitar os perigos e as fontes do mal.

Uma fonte que está completamente envenenada pela pestilência do mal e do pecado é a dansa.

Evitemos o baile e salvemos nossa alma imortal.

O que queres no baile? Dansar, só dansar por passatempo. Está bem; então, se és homem dansa com um homem, se és mulher, dansa com tua colega.
\end{abstract}

Ainda na década de 1950 há uma forte preocupação com a formação musical dos jovens. $\mathrm{O}$ ataque à dança como forma de tentação maligna ressaltava a popularidade da dança entre os jovens. Nota-se nesses artigos, uma preocupação com o gosto musical dos estudantes, já que a escola buscava difundir 
prioritariamente uma cultura musical erudita.

\section{OS ORFEÕES ESCOLARES NO GINÁSIO PARANAENSE/COLÉGIO ESTADUAL DO PARANÁ}

No início da década de 1930, os orfeões 4 foram se expandindo pelo país, mas com o advento do Estado Novo em 1937 e o apoio do ministro Gustavo Capanema essas práticas se intensificaram. Ainda em 1931, Villa-Lobos promoveu uma concentração orfeônica na capital paulista, chamada de Exortação Cívica. Durante, as décadas de 1930 a 1950 foram promovidas diversas solenidades cívicas com a participação dos orfeões escolares. Em Curitiba, essa prática também foi recorrente. Por meio de artigos publicados na imprensa local são analisadas questões como o teor das apresentações e o repertório executado pelos estudantes do Ginásio Paranaense. Esses arquivos foram encontrados em microfilmes na Biblioteca Pública do Paraná como parte do arquivo pessoal do maestro e professor da instituição Bento Mossurunga, que lecionou canto orfeônico no Ginásio Paranaense durante o recorte temporal proposto neste estudo.

Cronologicamente, o primeiro artigo encontrado trata-se de um texto publicado no Jornal de Antonina, que relata sobre as comemorações em homenagem ao maestro Carlos Gomes, organizada por alunos e professores do Ginásio Paranaense no ano de 1936:

O GYMNASIO PARANAENSE E AS COMEMORAÇÕES EM CARLOS GOMES

Programma de homenagem do corpo docente e diretor do Gimnasio

\footnotetext{
4 Os orfeões eram grupos corais, porém, de acordo com Valle (1936), enquanto o canto coral era voltado para profissionais e era exclusivamente de caráter erudito, havia o orfeão de índole popular, formados por grupos enormes de indivíduos e que não necessitavam saber música profissionalmente. Os orfeões, por estas características, se adequaram aos objetivos educacionais.
} 
Paranaense à memória do glorioso maestro Carlos Gomes, a realizar-se no dia 10/07/36, às 13:30 no salão nobre do mesmo Gymnasio.

I) Hymno Nacional, pelos alunos do curso de música do Gymnasio Paranaense, direcção do professor Bento Mussurunga (sic).

II) Dissertação sobre a música e a vida de Carlos Gomes pelo prof. Benedicto Nicolau dos Santos.

III) Hino à mocidade acadêmica, de Carlos Gomes cantado pelos alunos do Gymnasio Paranaense (JORNAL DE ANTONINA, 09/07/36).

A execução do Hino Nacional pelos colegiais sempre foi uma das principais exigências dos cursos de canto orfeônico. Assim, a execução do Hino Nacional tornou-se uma regra nas apresentações orfeônicas, até mesmo quando a história política da Pátria não era o tema principal do evento, caso desta apresentação em homenagem a Carlos Gomes.

No período do Estado Novo (1937-1945), as apresentações orfeônicas tiveram seu ápice no Brasil, devido ao número de apresentações e participantes nestes eventos. A posição favorável do ministro Gustavo Capanema em relação às grandes realizações orfeônicas promovidas por Villa-Lobos tornava-se também um fator determinante em relação à expansão dos orfeões escolares pelo Brasil. De acordo com a proposta de Capanema, na I Conferência Nacional de Educação, realizada em 1941:

[...] a Juventude brasileira teria na escola a sua 'base de funcionamento'; o 'ritmo de sua vida' seria estabelecido pelo seu calendário, graças ao qual 'todos os problemas', todos os ideais, todos os grandes nomes, todas as datas marcantes' seriam celebradas em seu dia, em todas as escolas do Brasil. Tais celebrações teriam maior ou menor solenidade, de acordo com a cidade, a escola ou a data a ser comemorada e deveriam, em geral, 'ser feitas rapidamente, em 10 ou 15 minutos'. As solenidades maiores, uma ou duas vezes por ano (BAIA HORTA, 2000, p. 161).

A preocupação do ministro Capanema com a juventude manteve-se ativa e relacionava-se intimamente com as apresentações orfeônicas. A homenagem a 
Carlos Gomes tornou-se um claro exemplo de homenagem aos grandes nomes brasileiros. O curto tempo de apresentação também se aproximava com o ideal pretendido por Capanema. Nota-se que a formação de orfeões acabava tornandose um poderoso instrumento a favor da escola, pois por muitas vezes, eram a atração principal das solenidades promovidas pelos colégios.

O artigo seguinte trata de um evento promovido pelo Ginásio Paranaense, em comemoração à recém-criada bandeira do Colégio, publicado pela Gazeta do Povo em 1939:

Após entrar no salão nobre e pavilhão alviverde, empunhado por uma ala do estabelecimento e guardado por um séquiito de honra pelas complementaristas, foi pomposamente entoado o hino oficial do Ginasio Paranaense. Cantou-se também entusiasticamente o hino da bandeira [...] E festivamente ecoou o hino da Independência. Seguindo o programa, o aluno Vinícius Vilas-Boas, da $3^{\mathrm{a}}$ série do curso fundamental, vibrou encantando o auditório com palavras flamejantes. Após do que, foi ouvido o hino acadêmico. Passou-se então à entrega da bandeira ao Ginásio, debaixo de vibrantes palmas, pelo prof. Dr. Pedro Macedo. Recebeu-a o Sr. Diretor Francisco José Gomes Ribeiro que, mediante palavras calorosas agradeceu e a transmitiu ao prof. Decano do estabelecimento, sr. Prof. Dr. Valdemiro Teixeira de Freitas que, por sua vez exaltou as belezas e as glórias do pendão nacional. Ecoou entusiástico, logo depois, o hino da bandeira, que como sempre foi dirigido pelo notável musicista maestro Bento Mossurunga (GAZETA DO POVO, 21/04/1939).

O discurso apresenta um teor nacionalista, exaltando os símbolos da Pátria. No texto, nota-se a preferência do repertório pelos hinos, sendo descartadas as canções regionais e folclóricas previstas pelas diretrizes nacionais do canto orfeônico. Além disso, em nenhum momento do artigo publicado pela Gazeta do Povo são exaltados aspectos relativos à música, como afinação ou desempenho dos alunos, com exceção da atuação do maestro Bento Mossurunga, apresentado como “[...] notável musicista” (GAZETA DO POVO, 1939).

Se, por um lado essas apresentações mostravam uma preocupação com o desenvolvimento da cidadania para os estudantes, por outro serviam de 
propaganda para o governo getulista, que apoiava publicamente essas manifestações e fazia-se adepto a proposta de propagação do orfeonismo pelo país. Segundo Contier (1998, p. 67-68):

Com o advento do Estado Novo, as concentrações orfeônicas tornaramse mais freqüentes e cada vez mais bem planejadas. A solenidade Hora da Independência, promovida para a comemoração do dia 7 de setembro de 1940, ilustra fase do apogeu desse tipo de manifestação. O projeto previa o comparecimento de 40.000 escolares e de 1.000 músicos da banda, no estádio de futebol do Vasco da Gama. O programa a ser apresentado incluía: Hino Nacional (Bandas), Oração do Presidente à Nação Brasileira, Hino Nacional (bandas e coros) e Hino à Independência; Oração Cívica (Saudação da Juventude Brasileira ao seu Guia: - Presidente Getúlio Vargas), Hino à Bandeira, Saudação Orfeônica à Bandeira, Inovação à Cruz (cívico-religioso); Coqueiral (Efeitos Orfeônicos); Meu Jardim (canção cívico-folclórica, de autoria de Ernesto dos Santos e David Nasser, solista de Francisco Alves); Ondas e Terror Irônico (efeitos orfeônicos); P'ra frente, ó Brasil! (canção cívica) e o Hino Nacional (bandas e coros). No final do espetáculo os escolares sairiam marchando e cantando (Regente: Heitor Villa-Lobos).

Certamente havia uma ênfase nacionalista nestas apresentações. No entanto, o conteúdo destas canções fez com que se vinculasse nas décadas seguintes o orfeonismo praticado no Brasil com aqueles praticados nos países totalitários como a Alemanha nazista de Hitler e a Itália fascista de Mussolini. Na Alemanha, no início da década de 1940, havia mais de 40.000 conjuntos corais, sendo que as canções executadas pelos orfeões assumiam um caráter iminentemente político, com alusões aos ideais arianos. O próprio Mário de Andrade, apoiador do ensino da música no Brasil, passou a demonstrar ressalvas com as concentrações orfeônicas brasileiras que assumiam uma postura semelhante aos corais alemães, transmitindo ideais políticos nas canções (LEMOS, 2017).

Por meio de outra publicação da Gazeta do Povo, em 30 de novembro de 1937, pode-se avaliar a lista de canções apresentadas no evento sobre a festa de encerramento do ano letivo no Ginásio Paranaense: 
José Cadilhe - Bento Mussurunga (sic) - Pátria Minha, Canção Patriótica pelo Orfeon do Ginásio.

Correia Jr. Bento Mussurunga (sic). Lindo Rincão. Canção Paranaense, pelo Orfeon do Ginásio.

E. Faria, M. With. Bento Mussurunga (sic). Brasil, Canção Patriótica. João da Glória, Lécio do Espírito Santo e coro.

Pixinguinha. Rancho Abandonado, Canção, Dilirmando Pereira.

Leocadio Correia/ Bento Mussurunga (sic) - Bom dia Paraná.

Bento Mussurunga (sic). Tempos Passados. Uma composição do autor, dedicado ao dr. Francisco Vilanueva. Conjunto Excelsior integrado pelos alunos do Ginásio.

Tarreza. Capricho árabe. Violão pelo sr. Altair Cavalcanti.

Julia Wanderley. O Semeador (declamação), Srta, Eunice dos Santos.

Chopin. Valsa op. Piano, srta, Iolanda Muzillo.

V. Henrique. A vela que passou, canção, João da Gloria.

Sá Pereiral. Por ti meu bem. Canção, Horacio Boscardim.

Ethelbert Werwin. Warlessus, piano., srta. Eora da Costa.

Rudolf Cordo. Canção Inlu. Canção, srta. Norma Moreira.

Chaminade. Lisongeira. Piano. Srta. Madalena Cristofel.

Luiz Moreira. Suplica. Canção. Srta. Eunice dos Santos.

B. Goulard. Mazurka $\mathrm{n}^{\mathrm{0}} 2$, piano, Milton Merry.

Correia Junior. B. Mossurunga. Variações sobre a saudade. Canto, Srta. Ondina Casagrande.

Silveira Neto, B. Mossurunga. Trova rústica. Canção regional. Srtas. Norma Moreira e Ondina Casagrande.

Hino Nacional pelo Orfeon do Ginásio e pessoas presentes.

Havia uma preocupação com a divulgação da música considerada de qualidade, sem deixar de contemplar os artistas populares preocupados com a tradição cultural das canções folclóricas. No entanto, nota-se que, se por um lado, havia a participação de músicos convidados, por outro, havia o orfeão destinado à parte solene das apresentações, ou seja, enquanto os convidados promoviam o espetáculo artístico, os orfeões promoviam o sentimento nacionalista por meio da execução de hinos e das canções cívicas. 
Em 1951, destaca-se a participação do orfeão do Colégio Estadual do Paraná em uma festa de encerramento da Semana da Arte, no qual o orfeão do Colégio Estadual executou o Hino à Árvore e o Hino de Curitiba (LEMOS, 2005). No ano de 1953, o jornal O Colégio Estadual do Paraná, organizado pelo Centro Estudantil da instituição, relatou a participação do orfeão executando o Hino do Colégio na festa realizada em homenagem ao Dia do Professor.

As intenções políticas vinculadas ao ensino do canto orfeônico acabaram dividindo opiniões dentro do campo da historiografia. Para Goldemberg (2002), Contier (1998), Paranhos (1997), houve uma forte associação entre o ensino de música, disciplina e civismo no período do Estado Novo, o que fez com que este ensino ficasse vinculado ao governo totalitário da época. As discussões em torno das intenções de Villa-Lobos ganharam destaque na historiografia, na qual pesquisadores como Goldemberg (2002) e Kiefer (1986) enfatizam as intenções artísticas, enquanto que Contier (1998) enfatiza as intenções políticas do maestro.

Outra questão que dificultou a expansão do ensino de Canto Orfeônico no Brasil foi o insuficiente número de profissionais habilitados para atuar como docente nas escolas secundárias brasileiras. Se nas décadas de 1930 e 1940 do século XX, havia a dificuldade de encontrar professores qualificados de Canto Orfeônico, na década seguinte o problema se agravou ainda mais, pois houve um aumento substancial no número de alunos matriculados nos ginásios brasileiros.

Nas aulas de Canto Orfeônico, nota-se a valorização da música erudita, apesar de que nas apresentações escolares, havia a preferência pela execução de canções de caráter cívico e hinos. Em relação à valorização da música erudita, alguns artigos encontrados no jornal O Colégio Estadual do Paraná são esclarecedores. Nestes artigos, muitos alunos fizeram alusões à música erudita como música de qualidade. No artigo Um Gênio Musical, em homenagem a Joham Sebastian Bach (1685-1750), nota-se a tentativa do autor de convencer aos estudantes das vantagens estéticas de apreciação da música erudita: 
A música de Bach é matematicamente perfeita. Não é por outro motivo que em todos os conservatórios e escolas adotam-se os seus métodos por serem os mais perfeitos e aproveitáveis. Suas composições não tem a beleza no sentido que empregamos ordinariamente, mas são ricas em perfeição na música orquestral, ainda hoje apreciados e comumente executados (O COLÉGIO ESTADUAL DO PARANÁ, 1953).

Os elogios a artistas da música erudita não são raros de encontrar nos periódicos estudantis. Desta forma, a matemática perfeita das composições de Bach, mesmo sem a beleza no sentido convencional, dispõe de elementos que a tornam uma música de qualidade. A música racional ganha força e é compartilhada por indivíduos conscientes da estética musical. No artigo A Boa Música no Rádio Brasileiro, de 1954, percebe-se esta preocupação com o nível estético dos programas de rádio:

Curioso de averiguar a quanto vai a vulgaridade da música divulgada pelas ondas hertzianas, um de nossos redatores incumbiu-se de organizar uma lista de maus programas. Como tal, porém, ocuparia o espaço de páginas inúmeras, devido à avalanche de mau gosto, ficou mais cômodo de curto anotar as audições que realmente se esmeram em apresentar a boa música.

É essa lista, que a título, não de crítica, porém de seleção, publicamos, recomendando-a à boa vontade dos leitores que desejam aprimorar sua cultura musical:

Álbum Sonoro - Rádio Guairacá, diariamente às 12,30. É um programa que atende ao pedido dos ouvintes.

Música dos Mestres - Rádio Gazeta de São Paulo, diariamente às 13,00. Uma hora da música mais erudita que já se compôs. Varia de gênero conforme o dia.

Festivais G. E. - Rádio Nacional, às quartas-feiras às 20,35. Trata-se de um dos mais tradicionais e antigos programas radiofônicos brasileiros, apresentando a orquestra sinfônica daquela emissora.

Relógio de Dona Música - Rádio Guairacá, quartas-feiras às 21,00 horas.

Música Divina - Rádio Guairacá, domingos às 9 horas da manhã (O COLÉGIO ESTADUAL DO PARANÁ, 1954).

Nota-se o ataque feito à maioria dos programas de rádio, acusados de 
emitirem conteúdos de "baixo valor estético". Entre os poucos programas eleitos, há uma preferência nítida pela música de caráter erudita. É certo que alguns dos programas não revelam o conteúdo musical, no entanto, o discurso agressivo quanto ao baixo nível estético das rádios, e a indicação de uma programação voltada à música erudita, revela uma resistência à música popular. Vale ressaltar que a existência de um programa que atendia ao pedido dos ouvintes, mostrava confiança da rádio no gosto musical de seu público, formado de estudantes secundaristas, representantes de uma elite cultural. Em 1959, o Colégio Estadual do Paraná já contava com uma rádio escolar, cuja programação é relatada no periódico O Colégio Estadual do Paraná:

$2^{\mathrm{a}}$ feira: - Às 20 horas, "Noticiário do Departamento de Turismo e Divulgação do Estado”. Em seguida, um variado. Às 20,30, “Ópera em Casa", até o encerramento.

$3^{\mathrm{a}}$ feira: - Às 20 horas, "Noticiário do Departamento de Turismo e Divulgação do Estado". Em seguida, programa da "Juventude Musical Brasileira Secção do Paraná". Ás 20,30, "Música de Câmera", até o encerramento.

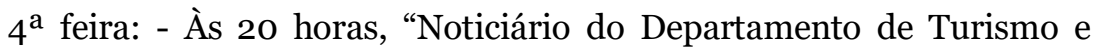
Divulgação do Estado". Em seguida, um variado. Às 20,30, "No Mundo da Sinfonia", até o encerramento.

$5^{\mathrm{a}}$ feira: - Às 20 horas, "Noticiário do Departamento de Turismo e Divulgação do Estado". Em seguida, "Música e Arte Alemãs". Às 20,30, "Noite de Concertos", até o encerramento.

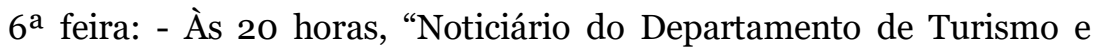
Divulgação do Estado". Em seguida, "Hora Franceza". Às 20,30, "No Reino da Operata", até o encerramento (O COLÉGIO ESTADUAL DO PARANÁ, 1959).

Novamente a presença da música erudita torna-se marcante. Cabia à escola a necessidade de formar um público conhecedor da música culta. Programas de rádio como estes podiam se difundir livremente nas escolas, uma vez que não deixavam de privilegiar as diretrizes nacionais do canto orfeônico no Brasil. 


\section{ESTRUTURA PARA O ENSINO DE MÚSICA E CANTO ORFEÔNICO NO GINÁSIO PARANAENSE/ COLÉGIO ESTADUAL DO PARANÁ}

Uma questão relevante para a prática do Canto Orfeônico é a estrutura disponível para a prática orfeônica. Não se pretende aqui, eleger uma possível falta de estrutura como o problema central do ensino de música na escola, pois “[...] nada permite afirmar que um súbito melhoramento dos locais, do mobiliário e do material teria modificado substancialmente e duravelmente as normas e as práticas de ensino." (CHERVEL, 1990, p. 195).

De acordo com a relação de materiais enumerados nas Estatísticas do Colégio Estadual do Paraná, em 1944, percebe-se que o piano não era o único equipamento ausente nas aulas de música. Para a cadeira de Música, o professor tinha a sua disposição apenas 32 Discos de orquestras e sinfonias, 10 caixas de agulhas, 1 escova para discos e 1 armário de imbuia (COLÉGIO ESTADUAL DO PARANÁ, 1944). Este equipamento referia-se aos acessórios necessários para aulas de apreciação e audição musical, conteúdos que de fato apresentavam-se contemplados e valorizados nas aulas de música (som, agulhas, discos). Porém, percebe-se claramente a carência de materiais para as aulas práticas de música, em que nem mesmo o diapasão, equipamento de baixo custo que oferece com precisão a nota lá, é encontrado como material disponível para o professor. No entanto, a carência não se resume à falta do diapasão, mas sim a ausência total de instrumentos musicais. Isto poderia ocasionar algumas dificuldades ao ensinar teoria musical como melodia, harmonia, intervalo, etc., já que não havia nenhum instrumento para exemplificar tais elementos. Desta forma, o professor poderia ser obrigado a trabalhar com um conceito muito abstrato da teoria musical, pois não havia à sua disposição, os recursos mínimos necessários para um ensino mais eficiente.

Destaca-se que a falta de material era um dos motivos de discussão ainda na década de 1930, quando Barreto relacionava a carência de recursos a uma consequente desmotivação do aluno: 


\begin{abstract}
A essa inadequação do material e a essa definição de execução, de efeitos negativos, por si mesmos, junte-se na ausência de verdadeira motivação para os exercícios do canto. Atraídas naturalmente para o canto, as crianças muitas vezes se enfadam dos cantos escolares, por não se haver considerado que o mais importante, no caso do aprendizado, como no de qualquer outra atividade escolar, é o seu interêsse real pelo que se pretende ensinar (BARRETO, 1938, p. 15).
\end{abstract}

A falta de material adequado poderia afetar na motivação dos alunos nas aulas de música. Essa certamente era uma das preocupações dos professores das instituições secundárias de Curitiba que solicitavam por novos materiais e recursos em prol do ensino de música e canto orfeônico.

Outra questão importante em relação à estrutura para o ensino de música e canto orfeônico é o espaço escolar, pois os ensaios traziam um grande problema espacial para a escola, já que segundo Barreto (1938) a falta de um local apropriado ao estudo de música, poderia prejudicar aulas de outras disciplinas.

O espaço autônomo para a prática dos orfeões não era necessário apenas para abrigar adequadamente as grandes turmas, que muitas vezes chegavam a 50 (cinquenta) alunos, mas também porque a atividade necessitava de adaptações no ambiente, como por exemplo, a retirada de carteiras e cadeiras. Além disso, outras questões são de extrema relevância, caso da necessidade de isolamento acústico da sala, uma vez que o som emitido pelo coro poderia atrapalhar a eficiência e a concentração dos alunos de outras turmas.

No Colégio Estadual do Paraná foi apenas no ano de 1950 que o espaço para a prática orfeônica passou a ser contemplado. Isso ocorreu quando o Colégio Estadual do Paraná mudou de sede e passou a contar com um maior e mais adequado espaço físico. Segundo o governador Moysés Lupion, por ocasião da abertura ordinária da Assembleia Legislativa do Estado em 1950:

Desse modo, e com esse espírito, subdividimos a direção do estabelecimento em vários serviços e esperamos que a simples enunciação de tais serviços possa dar uma idéia dos nossos propósitos: atividades administrativas propriamente ditas; atividades culturais, 


\begin{abstract}
com concertos, conferências, teatro do estudante, pintura, ballet, canto coral, discoteca e festividades; atividades de associações e instituições escolares, com cooperativa, cantina, jornal, clubes diversos, colônia de férias, associação de ex-alunos, excursões e oficinas; atividades científicas, com laboratórios, biblioteca, cinema educativo, museus; atividades de orientação, educação física, com ginasium, piscinas, estádio de desportos, olimpíada colegial e atividades de assistência, compreendendo a médica, dentária e social (LUPION apud STRAUBE, 1993, p. 111).
\end{abstract}

Cada uma das sessões acima citadas mantinha um local de funcionamento adequado, pois havia uma preocupação com a descentralização da direção do Colégio Estadual do Paraná, devido às grandes proporções desta nova sede. Durante toda a década de 1930 e 1940, o Colégio não havia contado com uma ampla estrutura espacial. No entanto, a preocupação com um espaço autônomo para a prática vocal, mesmo que tardiamente, demonstra a afirmação da disciplina no Colégio Estadual do Paraná, que se preocupava em oferecer uma estrutura necessária para as aulas de canto orfeônico.

\title{
CONSIDERAÇÕES FINAIS
}

Mesmo que em Curitiba as apresentações orfeônicas não representem a mesma amplitude do que as promovidas por Villa-Lobos, ainda assim foram amplamente valorizadas. O teor nacionalista esteve presente no período do Estado Novo, buscando a conformação do estudante frente ao Governo ditatorial. Entre as diferentes estratégias para atingir este objetivo está a exaltação popular à Pátria. Nesse sentido, a música entre a Era Vargas (1930-1945) foi utilizada como forma de propaganda da política Getulista, tornando-se um poderoso instrumento nas mãos dos ideólogos do Governo. Com o término do período do Estado Novo em 1945, as apresentações dos orfeões curitibanos, assim como o ensino de canto orfeônico na escola, persistiram. A atuação incondicional de Villa-Lobos prosseguiu até o ano de sua morte em 1959, independente da política adotada pelo país. No ano de 1961 com a promulgação da LDB n. ${ }^{\circ}$ 4024/61 o 
ensino de música se tornou optativo na escola e não mais se apresentando como canto orfeônico.

O ensino de canto orfeônico, mesmo que privilegiando a cultura nacional por meio de elementos folclóricos, elegeu a música erudita como a detentora de qualidade estética elevada. Em oposição à música de apelo comercial, as emissoras e programas de rádio acabaram por ser alvo de críticas por parte dos estudantes secundários do Colégio Estadual do Paraná, que representavam uma elite, tendo em vista que a maioria da população brasileira das décadas contempladas neste estudo não possuía sequer o nível primário concluído. Por fim, percebe-se o empenho do Ginásio Paranaense na divulgação do canto orfeônico. O Paraná mostrava-se sintonizado ao projeto nacional em prol do ensino de música ocorrido após a década de 1930.

\section{REFERÊNCIAS}

A BOA música no rádio brasileiro. O Colégio Estadual do Paraná, Curitiba, mai./jun. 1954. n. 69, ano XIV.

A RADIO emissora do Colégio Estadual do Paraná. O Colégio Estadual do Paraná, Curitiba, Jul. 1959, n. 88, ano XVIII.

BAIA HORTA, José Silvério. A I Conferência Nacional de Educação ou de como monologar sobre educação na presença de educadores. In: GOMES, Angela de Castro (org.). Capanema: o ministro e seus ministérios. Rio de Janeiro: FGV, 2000.

BARRETO, Ceição de Barros. Côro orfeão. São Paulo: Companhia Melhoramentos, 1938.

BORROMEU, Padre. É pecado dansar? O Domingo: seminário católico para as famílias, Curitiba, 04 set. 1955. Ano XXIII, fasc. 9, n. 36.

BRASIL. Decreto-lei n. ${ }^{\circ}$ 9.494, de 22 de julho de 1946. A Lei Orgânica do Ensino de Canto Orfeônico. Diário Oficial da União. 27. jul. 1946.

CHERVEL, André. História das disciplinas escolares: reflexões sobre um campo 
de pesquisa. Teoria e educação, Porto Alegre, n. 2, p. 177-229, 1990.

COLÉGIO ESTADUAL DO PARANÁ. Ata de resultados finais de fevereiro de 1953. Curitiba, 1953.

COLÉGIO ESTADUAL DO PARANÁ. Estatísticas sobre o Colégio Estadual do Paraná referentes ao ano de 1944. Curitiba, 1944.

COLÉGIO ESTADUAL DO PARANÁ. Relatório de novembro/dezembro de 1946 do curso ginasial. Curitiba, 1946.

COLÉGIO ESTADUAL DO PARANÁ. Relatório de novembro/dezembro de 1946 do curso ginasial. Curitiba, 1946.

COLÉGIO ESTADUAL DO PARANÁ. Relatório do mês de março de 1935. Colégio Estadual do Paraná. Curitiba, 1935.

COLÉGIO ESTADUAL DO PARANÁ. Relatório do mês de março de 1936. Curitiba, 1936.

COLÉGIO ESTADUAL DO PARANÁ. Relatórios dos meses de abril, maio e junho de 1947 do curso ginasial e colegial. Curitiba, 1947.

COLÉGIO ESTADUAL DO PARANÁ. Relatórios dos meses de janeiro, fevereiro, março de 1946 ( $1^{\circ}$ Volume) do curso ginasial e colegial. Curitiba, 1946.

COLÉGIO ESTADUAL DO PARANÁ. Relatórios dos meses de janeiro, fevereiro, março e abril de 1946 ( $2^{\circ}$ Volume) do curso ginasial e colegial. Curitiba, 1946.

COLÉGIO ESTADUAL DO PARANÁ. Relatórios dos meses de janeiro, fevereiro, março de 1947 ( $1^{\circ}$ Volume) do curso ginasial e colegial. Curitiba, 1947.

COLÉGIO ESTADUAL DO PARANÁ. Relatórios dos meses de janeiro, fevereiro, março e abril de 1946 do curso ginasial e colegial. Curitiba, 1946.

COLÉGIO ESTADUAL DO PARANÁ. Relatórios dos meses de janeiro, fevereiro, março de 1947 do curso ginasial e colegial. Curitiba, 1947.

COLÉGIO ESTADUAL DO PARANÁ. Relatórios dos meses de novembro e dezembro de 1945 do Curso Ginasial e Colegial. Curitiba, 1945.

COLÉGIO ESTADUAL DO PARANÁ. Relatórios dos meses de outubro, 
novembro e dezembro de 1947 do curso ginasial e colegial. Curitiba, 1947.

CONTIER, Arnaldo Daraya. Passarinhada do Brasil: canto orfeônico, educação e getulismo. Bauru: Edusc, 1998.

ENCERRAM-SE de maneira brilhante as comemorações da "semana da árvore". Arquivos de Bento Mossurunga. Curitiba: Biblioteca Pública do Paraná, 1953. 1 bobina de microfilme: neg.

FESTA de encerramento do ano letivo no Ginásio Paranaense. Gazeta do Povo, Curitiba, 30 nov. 1937.

GOLDEMBERG, Ricardo. Educação musical: a experiência do canto orfeônico no Brasil. Disponível em: http://www.sambachoro.com.br/print/debates/1033405862/index_hrml. Acesso em: 9 jun. 2003.

IGAYARA-SOUZA, Susana Cecilia. Objetivos artísticos do canto orfeônico no Brasil. In: ROCHA, Inês de Almeida; IGAYARA-SOUZA, Susana Cecilia; MONTI, Ednardo Monteiro Gonzaga do (org.). Sons de outrora em reflexões atuais: história da educação e música. Curitiba: CRV, 2020.

KIEFER, Bruno. Villa-Lobos e o modernismo na música brasileira. 2. ed. Porto Alegre: Movimento; Brasília: INL, 1986.

LEMOS JUNIOR, Wilson. Canto orfeônico: uma investigação acerca do ensino de música na escola secundária pública de Curitiba (1931-1956). 2005. 111 f. Dissertação (Mestrado em Educação) - Programa de Pós-Graduação em Educação, Universidade Federal do Paraná, Curitiba, 2005.

\section{LEMOS JUNIOR, Wilson. História da formação de professores de} música: o contexto paranaense. Curitiba: Appris, 2017.

MONTI, Ednardo Monteiro Gonzaga do; ROCHA, Inês de Almeida. Convite à escutas, lembranças e memórias. In: MONTI, Ednardo Monteiro Gonzaga do; ROCHA, Inês de Almeida (org.). Ecos e memórias: histórias de ensinos, aprendizagens e músicas. Teresina: EDUFPI, 2019.

O DIA da bandeira no Ginásio Paranaense. Gazeta do Povo, Curitiba, 21 abr. 1939.

O DIA do professor. O Colégio Estadual do Paraná, Curitiba, out. 1953. n. 67 , ano XIII.

O GYMNASIO Paranaense e as comemorações em Carlos Gomes. Jornal de 
Antonina, Antonina, o9 jul. 1936.

PARANHOS, André. O coro da unanimidade nacional: o culto ao Estado Novo. Revista de sociologia e política: Estado Novo (1937-1945). Curitiba, n. 9: Ed. da UFPR, 1997.

SEVCENKO, Nicolau. Literatura como missão: tensões sociais e criação cultural na primeira república. São Paulo: Brasiliense, 1999.

SOUZA JUNIOR, Marcílio; GALVÃO, Ana Maria de Oliveira. História das disciplinas escolares e história da educação: algumas reflexões. Educação e Pesquisa, São Paulo, v. 31, n. 3, set./dez. 2005. Disponível em: http://www.scielo.br/scielo.php?script=sci_arttext\&pid=S151797022005000300005\# end. Acesso em: 27 abr. 2020.

STRAUBE, Ernani Costa. Do Licêo de Coritiba ao Colégio Estadual do Paraná: 1846-1993. Curitiba: Fundepar, 1993.

VALLE, Flausino Rodrigues. Elementos do folk-lore musical brasileiro. São Paulo: Companhia Editora Nacional, 1936.

WILSON LEMOS JUNIOR é doutor em Educação pela Pontifícia Universidade Católica do Paraná (PUC-PR) e mestre em Educação pela Universidade Federal do Paraná (UFPR). Professor do Instituto Federal do Paraná Campus Curitiba (IFPR). Desenvolve pesquisas na linha de História e Políticas da Educação, em especial sobre a história do ensino de música e sobre a história da educação profissional no Brasil. Licenciado em Educação Artística com Habilitação em Música pela Faculdade de Artes do Paraná (FAP). Professor permanente e atualmente coordenador do Programa de Pós-graduação em Educação Profissional e Tecnológica (ProfEPT). Instituição Associada: Instituto Federal do Paraná.

E-mail: juniorlem@gmail.com

(1) http://orcid.org/0000-0002-3566-9113

Recebido em: 15 de novembro de 2019

Aprovado em: 25 de julho de 2020

Revista História da Educação - RHE

Associação Sul-Rio-Grandense de Pesquisadores em História da Educação - Asphe

Artigo de acesso aberto distribuído nos termos de licença Creative Commons. 